\title{
A Quantitative Assessment of Precipitation Mechanisms of Thunderstorm Electrification
}

\author{
By J. Latham \\ Physics Department, University of Manchester, Institute of Science and Technology, England \\ (Manuscript received 20 October 1970)
}

\begin{abstract}
Calculations based on both the Marshall-Palmer distribution equation and the concentrations of solid and liquid hydrometeors compiled by Sartor (1967), have been made of the contributions made by precipitation particles of different sizes to the charging rate, the maximum volume charge density on precipitation and the precipitation current produced within a cloud when a precipitation mechanism of electrification is operating.

It was found that at all stages during the growth of the cloud the dimensions of the precipitation particles which provide the major contribution to the electrification are small. For a precipitation rate of $10 \mathrm{~mm} \mathrm{hr}^{-1}$ the primary contribution is made by particles of less than 0.1 $\mathrm{cm}$ diameter and even in immensely active clouds with a precipitation rate of $200 \mathrm{~mm} \mathrm{hr}^{-1}$ the optimum diameter is below $0.2 \mathrm{~cm}$. On the other hand, the diameter of precipitation particles which provide the major contribution to the radar echo intensity increases from 0.25 to $0.42 \mathrm{~cm}$ as the precipitation rate increases from 10 to $200 \mathrm{~mm} \mathrm{hr}^{-1}$.

Calculations showed that the values of precipitation current and volume charge density which several workers have shown to be essential requirements of a tenable theory of thunderstorm electrification can be achieved by a precipitation mechanism operating with a precipitation rate of only about $15 \mathrm{~mm} \mathrm{hr}^{-1}$, which corresponds to a precipitation water content of around 0.8 gm $\mathrm{m}^{-3}$.
\end{abstract}

\section{Introduction}

Until recently it was generally accepted that the electrification of thunderclouds was primarily a consequence of the interaction of large and small hydrometeors resulting in charge transfer. Subsequent separation of the oppositely charged particles of different sizes then gave rise to the development of an electric field within the cloud. Although serious disagreement existed as to the dominant mechanism of charge transfer involved, the assumption that precipitation development was centrally involved in cloud electrification was rarely questioned.

Subsequently, however, theories of cloud electrification were composed, principally by Grenet (1947), Vonnegut (1953), Phillips (1967a, b) and Colgate (1967) which in different degrees, attributed the electrical development to the dynamical structure of the cloud and assumed that the role of precipitation was secondary. Unfortunately, current knowledge of the meteor- ological and electrical properties of thunderstorms, together with the air motions within and around them is insufficient to establish definitively which of these two classes of mechanisms is more important. However,Vonnegut (1963, 1965a, b, c) has exposed a possible limitation of the precipitation mechanisms which can be explored with reasonable precision. He argued that since the maximum charge that can be carried on a spherical particle is proportional to the square of its radius it is grossly inefficient to separate charge on larger hydrometeors, which have very low surfacevolume ratios. The purpose of this paper is to subject this criticism to quantitative test, and to determine the values of precipitation rates and hydrometeor water concentrations which must exist within clouds in order to generate and separate charge at a rate required by an acceptable theory of thunderstorm electrification. A further objective is to determine the size-ranges of precipitation particles which provide the largest contribution to the electrification. 


\section{Calculations of cloud electrification and radar echo intensity}

In order to calculate the electrical development within clouds produced by the interaction of larger particles with smaller ones, it is necessary to assume a precipitation-particle size distribution which preferably can be expressed as a functional relationship. Equations determined empirically by several workers have been discussed by Mason (1957). In the case of liquid precipitation a convenient expression is that presented by Marshall and Palmer (1948) which predicts an increase in the median diameter with increasing precipitation intensity. It is certainly true that the drop-size distribution within a cloud will not, in general, be in precise agreement with the Marshall-Palmer equation; and the discrepancies will be greater in the case of the distribution of ice particles. However, it appeared reasonable to assume that, in view of the crudity of the calculations presented in this paper, that the Marshall-Palmer equations provide sufficiently accurate values of the particle-size distributions. As a check on this assumption calculations were also made using the concentrations of solid and liquid precipitation particles compiled by Sartor (1967) for mature thunderstorms.

Marshall and Palmer showed that $N(D) \delta D$, the concentration of drops of diameter between $D$ and $D+\delta D$ is related to the precipitation rate $p$ by means of the expression

$$
N(D) \delta D=8 \times 10^{-2} \exp \left(-41 D \cdot p^{-0.21}\right)
$$

where $N(D)$ is measured in $\mathrm{cm}^{-3}, D$ in $\mathrm{cm}$ and $p$ in $\mathrm{mm} \mathrm{hr}^{-1}$. Concentrations of raindrops of diameter ranging from $0.01 \mathrm{~cm}$ to $0.5 \mathrm{~cm}$ were determined from equation (1) for precipitation rates ranging from $1 \mathrm{~mm} \mathrm{hr}-1$, which would exist in the very early stages of development of a thunderstorm, to $200 \mathrm{~mm} \mathrm{hr}^{-1}$, which may occur under extreme conditions in the mature phase. It is sometimes more convenient to work with the precipitation water content, $L$, instead of the precipitation rate $p$, so Table 1 presents the relationship between these two parameters. The values of $L$ were determined from the equation

$$
L=\sum_{D_{\min }}^{D_{\max x}}(\pi / 6) D^{3} \sigma N(D) \delta D
$$

where $\sigma$ is the density of water and the limiting
Table 1 The variation of the total precipitation water content, $L$, with the precipitation rate $p$, Marshall-Palmer distribution.

\begin{tabular}{l|l|l|l|l|l|l|l|l|l|l}
\hline$p\left(\begin{array}{l}\mathrm{mm} \\
\mathrm{hr}^{-1}\end{array}\right)$ & 1 & 5 & 10 & 20 & 30 & 40 & 50 & 70 & 100 & 200 \\
\hline$L\left(\begin{array}{l}\mathrm{gm}_{\mathrm{m}}^{-3} \\
\text { m }\end{array}\right.$ & 0.10 & 0.34 & 0.61 & 1.10 & 1.54 & 1.96 & 2.36 & 3.12 & 4.18 & 7.29 \\
\hline
\end{tabular}

diameters $D_{\min }$ and $D_{\max }$ were arbitrarily chosen to be 0.01 and $0.5 \mathrm{~cm}$ respectively. It can easily be shown that with a Marshall-Palmer distribution the values of $L$ are insensitive to any reasonable modifications to $D_{\min }$ and $D_{\max }$.

In order to calculate the rate of development of the electrification of the clouds it is necessary to propose a relationship between the diameter of a raindrop and charge transfer $q$ produced when it interacts with a cloud droplet. The equation selected was

$$
q=K D^{n}
$$

where $K$ is a constant and $n$ is a factor which depends upon the charging mechanism under consideration. The rate of charging of unit volume of the cloud produced by drops of diameter varying from $D$ to $D+\delta D$, falling at their terminal velocity $V$ and interacting with non-precipitating particles can be expressed in arbitrary units by the equation

$$
A(D) \delta D=D^{2+n} V N(D) \delta D
$$

It should be stressed that absolute values of charging rate cannot be obtained from equation (4), which provides relative values of $A(D) \delta D$ as a function of particle-size and precipitation rate. Equation (4) is based on the assumptions that the collection efficiencies of the raindrops are independent of $D$ and that they will separate from the non-precipitating particles at their terminal velocities. These assumptions are not strictly correct and will tend slightly to exaggerate the importance of the smaller raindrops in the electrical development. On the other hand, the Marshall-Palmer equation underestimates the concentrations of smaller raindrops, particularly when the precipitation rate is low. It is reasonable to assume, therefore, that equation (4) provides a sufficiently precise description of the relative contributions to the total charging rate of raindrops of different sizes. The values of $A$ can be given only in arbitrary units because exact numerical 
values will vary with the charging mechanism, the small-particle concentrations and other factors. The values of $V$ utilized were taken from Gunn and Kinzer (1949).

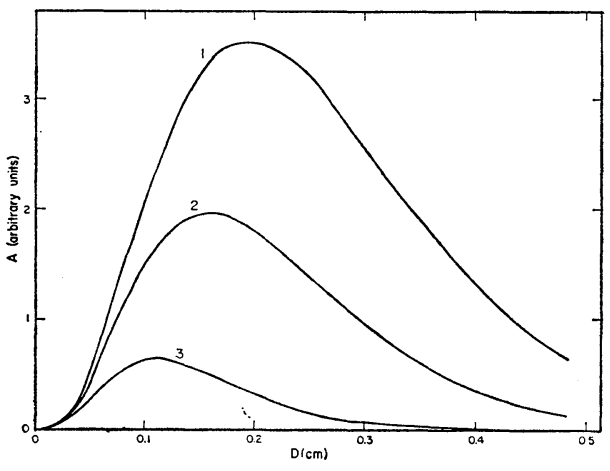

Fig. 1. The variation of charging rate $A(=A(D) \delta D)$ with drop diameter $D$ at various precipitation rates $p$. Marshall-Palmer distribution.

$n=0$.

Curve 1, $p=200 \mathrm{~mm} \mathrm{hr}^{-1}$;

2, $p=70 \mathrm{~mm} \mathrm{hr}^{-1}$;

$3, p=10 \mathrm{~mm} \mathrm{hr}^{-1}$.

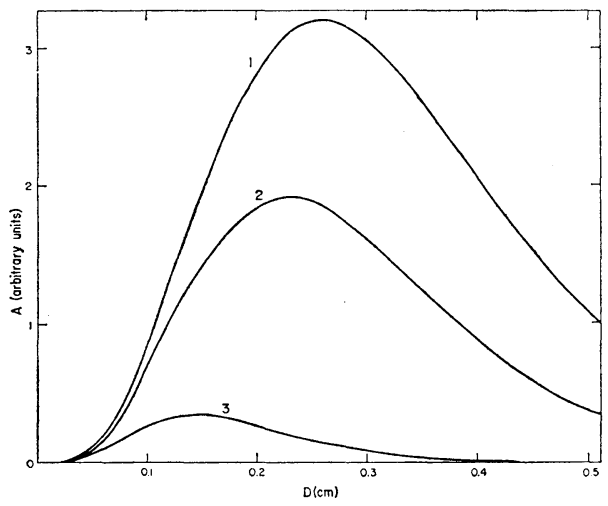

Fig. 2. The variation of charging rate $A(=A(D) \delta D)$ with drop diameter $D$ at various precipitation rates $p$. Marshall-Palmer distribution. $n=1$.

Curve 1, $p=200 \mathrm{~mm} \mathrm{hr}^{-1}$;

2, $p=70 \mathrm{~mm} \mathrm{hr}^{-1}$

3, $p=10 \mathrm{~mm} \mathrm{hr}^{-1}$.

Figs. 1 and 2 show the predicted variation of charging rate with raindrop diameter for $n=0$ and $n=1$ respectively. It is seen that in both cases the value of $D$ which contributes most to the charging rate increases with increasing precipitation rate but that throughout the development of a thundercloud of typical dimensions the particles which play the major role are less than about $2 \mathrm{~mm}$ in diameter. This fact can be seen more clearly from Fig. 3 which presents

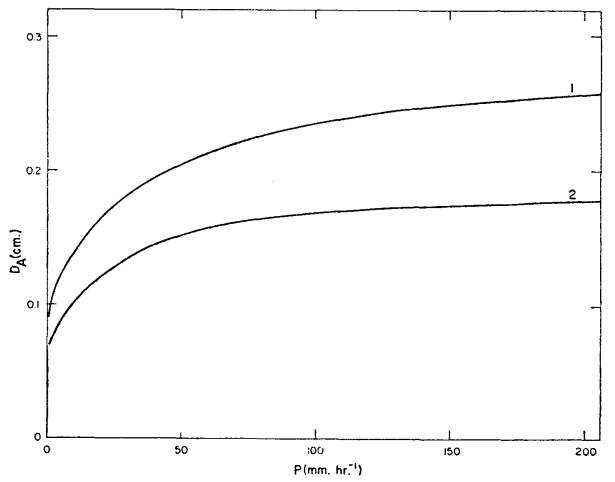

Fig. 3. The variation with precipitation rate $p$ of the drop diameter $D_{A}$ which provides the largest contribution to the charging rate. Marshall-Palmer distribution.

Curve $1, n=0 ; 2, n=1$.

the variation with precipitation rate of the diameter $D_{A}$ providing the largest contribution to the charging rate. During the growth stages of a cloud the most important particles are around $1 \mathrm{~mm}$ in diameter, and even when the precipitation rates are immense the raindrops which contribute most significantly to the charging are quite small. The variation of $n$ from 0 to 1 is seen to have a discernible but not major effect on the curves. The correct value of $n$ will depend upon charging mechanism. For inductive mechanisms involving the transient collision of cloud particles $n$ will be close to zero. Experiments have indicated that for the Reynolds-Brook mechanism $n$ will be less than but near to unity, whereas $n$ will be close to zero for the dropsplintering process. For ion-capture, which is a special case of the inductive mechanism, involving the interaction of precipitation particles with ions, $n$ is equal to zero. Insufficient evidence precludes a determination of $n$ for other precipitation mechanisms, but the values will probably lie between zero and unity. It seemed reasonable, therefore, particularly in view of the insensitivity of the relative charging rates to values of $n$, to take $n=0$ for all subsequent calculations.

One parameter which can be determined accurately if the raindrop concentrations and size distributions are known is the maximum volume 
charge density carried on precipitation within the cloud. In order to make this calculation we require to know the maximum charge $Q_{\max }$ which can be carried on a raindrop of diameter $D$. Measurements of the actual charges on raindrops, made by several workers, together with considerations of corona limitation combine to suggest that a reasonably accurate value for $Q_{\max }$ in e. s. u. is given by the equation

$$
Q_{\max }=5 D^{2}
$$

The product of the maximum charge on a raindrop of diameter $D$ and the number of raindrops possessing a diameter between $D$ and $D+\delta D$ therefore gives $S(D) \delta D$, the maximum volume charge density which can be carried on precipitation within this size range. This relationship is described by the equation

$$
S(D) \delta D=4 \times 10^{5} D^{2} \exp \left(-41 D \cdot p^{-0.21}\right)
$$

where $S(D) \delta D$ is measured in e. s. u. $\mathrm{m}^{-3}$. It should be pointed out that although $A(D) \delta D$ could be determined only in arbitrary units, equation (6) provides quantitative values of $S(D) \delta D$.

Solutions of equation (6) are presented in curves 1,2 and 3 of Fig. 4 . It is seen that the value of $D$ which contributes most to the maximum volume charge density on precipitation increases

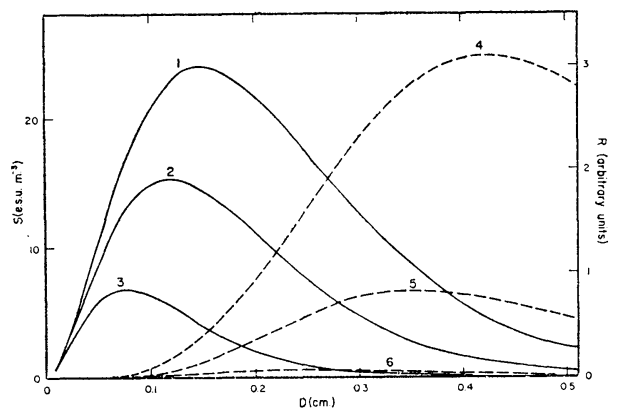

Fig. 4. The variation of maximum volume charge density $S(=S(D) \delta D)$ and radar echo intensity $R(=R(D) \delta D)$ with drop diameter $D$ at various precipitation rates. Marshall-Palmer distribution.

Curve 1, $S, p=200 \mathrm{~mm} \mathrm{hr}^{-1}$;

2, $S, p=70 \mathrm{~mm} \mathrm{hr}^{-1}$;

3, $S, p=10 \mathrm{~mm} \mathrm{hr}^{-1}$;

4, $R, p=200 \mathrm{~mm} \mathrm{hr}^{-1}$;

5, $R, p=70 \mathrm{~mm} \mathrm{hr}^{-1}$;

6, $R, p=10 \mathrm{~mm} \mathrm{hr}^{-1}$. with increasing precipitation rate but for all values of $p$ is below that providing the largest contribution to the charging rate. This finding is a consequence of the fact that the higher terminal velocities of larger particles will increase their charging rates but not the saturation charge that they can carry. In thunderclouds of moderate intensity the great majority of the charge will be carried on raindrops of diameter less than $2 \mathrm{~mm}$, and in the early stages of .growth most of the charge can be located on particles of diameter below $1 \mathrm{~mm}$. This conclusion is shown more clearly in Fig. 5 which illustrates the predicted

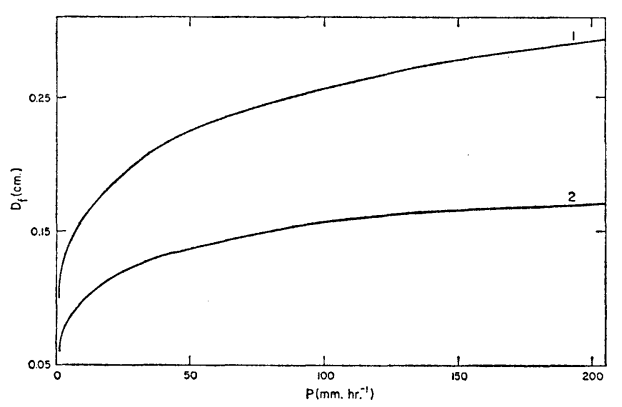

Fig. 5. The variation with precipitation rate $p$ of the drop diameter $D_{f}$ below which a fraction $f$ of the total charge is located. Marshall-Palmer distribution.

Curve $1, f=0.8 ; 2, f=0.5$.

variation with precipitation rate of the diameter $D_{f}$ below which 0.8 and 0.5 of the total maximum charges on precipitation resides. The role of very large raindrops in cloud electrification is again seen to be negligible.

Sartor (1967), in a study of the inductive mechanism of cloud electrification, compiled from the measurements of several workers tables listing the size distributions and concentrations of solid and liquid hydrometeors within mature thunderclouds. This information was used in the present study to compute values of $A(D) \delta D$ and $S(D) \delta D$ for water drops and ice particles, which could be compared with those obtained using the MarshallPalmer distribution equation. The results of these calculations are presented in Figs. 6 and 7. It is seen that in the case of electrification produced by interactions between raindrops and cloud droplets the major contribution to both the charging rate and the maximum volume charge density is provided by drops of diameter ranging 


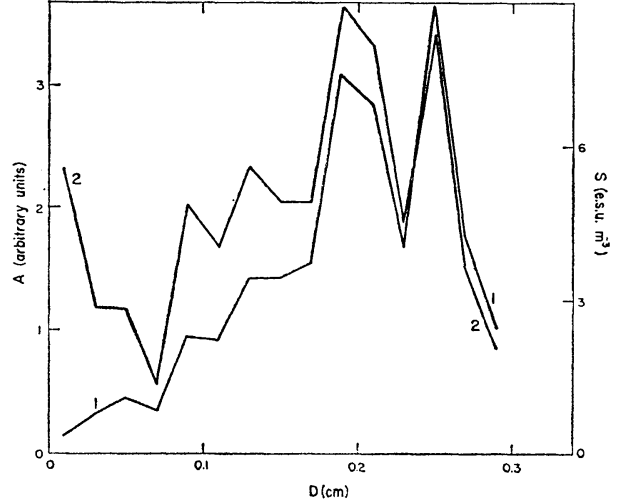

Fig. 6. The variation of charging rate $A(=A(D) \delta D)$ and maximum volume charge density $S(=S(D) \delta D)$ with drop diameter $D$ in mature thunderstorms. Distribution based on Sartor (1967). $n=0$.

Curve $1, A ; 2, S$.

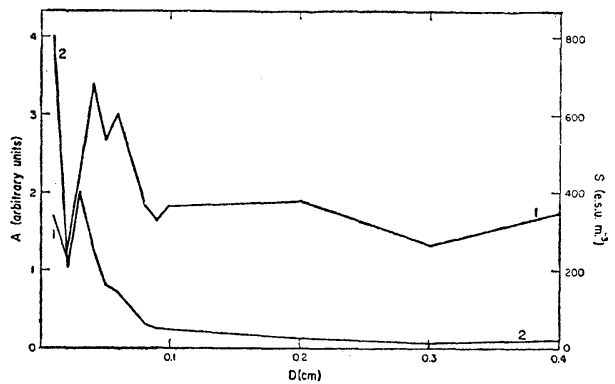

Fig. 7. The variation of charging rate $A(=A(D) \delta D)$ and maximum volume charge density $S(=S(D) \delta D)$ with ice crystal diameter $D$ in mature thunderstorms. Distribution based on Sartor (1967). $n=0$. Curve $1, A ; 2, S$.

from about 0.2 to $0.25 \mathrm{~cm}$. In the case of ice particle interactions the major contributions are made by solid hydrometeors of diameter considerably below $0.1 \mathrm{~cm}$. Although Sartor's estimated concentrations of ice particles were uncertain and the role of large particles may in fact be greater than is suggested by Fig. 6 it is nevertheless apparent that the smaller solid precipitation particles make the major contribution to the electrical development. The predictions resulting from the use of Sartor's concentrations are therefore in good agreement with those emanating from the calculations based on the Marshall-Palmer distribution.

The intensity of the radar echo from drops of diameter between $D$ and $D+\delta D$ can be expressed in arbitrary units by means of the equation

$$
R(D) \delta D=D^{6} N(D) \delta D
$$

It should be noted that absolute values of radar echo intensity cannot be obtained from equation (7), which provides relative values of $R(D) \delta D$ as a function of dropsize. Solutions of equation (7) obtained using the Marshall-Palmer equation are presented in Fig. 4. It is seen that for precipitation rates of $10 \mathrm{~mm} \mathrm{hr}^{-1}, 70 \mathrm{~mm} \mathrm{hr}^{-1}$ and 200

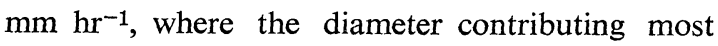
to the maximum volume charge density is 0.08 , 0.12 and $0.15 \mathrm{~cm}$ respectively, the corresponding diameter which provides the major contribution to the radar return signal is $0.25,0.35$ and 0.42 $\mathrm{cm}$. The particles of major importance in the electrical development of the cloud are shown to provide an insignificant contribution to the radar signal, and vice-versa. This fact is illuminated in Fig. 8 which exposes, over the entire range of

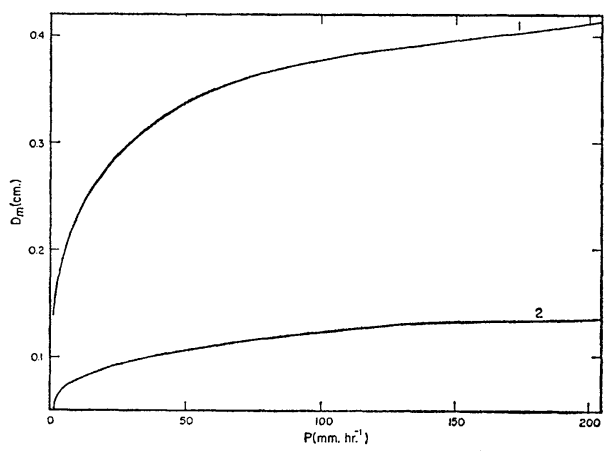

Fig. 8. The variation with precipitation rate $p$ of the drop diameter $D_{m}$ which provides the largest contribution to the radar echo intensity (Curve 1) and the maximum volume charge density (Curve 2). Marshall-Palmer distribution.

precipitation rates studied, the enormous gulf between the drop sizes providing the major contribution to the radar echo intensity and to the maximum volume charge density. No calculations of $R(D) \delta D$ were made for ice particles.

A further distinction between the development of precipitation, as observed by radar, and of the electrification of clouds is illustrated in Table 2. It is seen that whereas the maximum volume charge density increases by factors of 2.6, 5.2 and 9.3 as the precipitation rate increases from 1 to 
Table 2 The rates of increase of $S_{\max }$, the highest contribution to the maximum volume charge density, and $R_{\max }$, the highest contribution to the radar echo intensity, with precipitation rate $p$. MarshallPalmer distribution.

\begin{tabular}{|c|c|c|c|}
\hline $\begin{array}{c}p \\
\left(\mathrm{~mm} \mathrm{hr}^{-1}\right)\end{array}$ & $\begin{array}{c}S_{\max } \\
\left(\begin{array}{c}\text { arbitrary } \\
\text { units }\end{array}\right)\end{array}$ & $\begin{array}{c}R_{\max } \\
\left(\begin{array}{c}\text { arbitrary } \\
\text { units }\end{array}\right)\end{array}$ & $\begin{array}{l}R_{\max } / S_{\max } \\
\left(\begin{array}{c}\text { arbitrary } \\
\text { units }\end{array}\right)\end{array}$ \\
\hline 1 & 1 & 1 & 1 \\
\hline 5 & 1. 9 & 7.5 & 3. 9 \\
\hline 10 & 2. 6 & 18 & 6.9 \\
\hline 20 & 3. 6 & 42 & 11.7 \\
\hline 30 & 4. 1 & 71 & 17. 3 \\
\hline 40 & 4. 8 & 102 & 21. 3 \\
\hline 50 & 5. 2 & 135 & 26.0 \\
\hline 70 & 6.0 & 206 & 34. 3 \\
\hline 100 & 6.9 & 323 & 46.8 \\
\hline 200 & 9. 3 & 775 & 83.3 \\
\hline
\end{tabular}

10, 50 and $200 \mathrm{~mm} \mathrm{hr}^{-1}$ respectively the corresponding increases in the radar echo intensity are 18,135 , and 775 . The rate of increase in the intensity of the radar signal from drops is therefore much more rapid than the rate of growth of fields within clouds, produced by the interaction of precipitation with smaller hydrometeors.

\section{Discussion}

In order to determine whether precipitation mechanisms can be quantitatively adequate to carry and separate the required amount of charge within clouds it is necessary to determine $\rho$, the maximum volume charge density on precipitation particles within clouds, and $I$, the current that can be transported through the cloud on precipitation. These parameters can be expressed in quantitative terms by means of the equations

$$
\rho=\sum_{D_{\min }}^{D_{m a x}} S(D) \delta D
$$

and

$$
I=\sum_{D_{\min }}^{D_{\max }} S(D) \cdot V \cdot \delta D
$$

where $D_{\min }=0.01 \mathrm{~cm}$ and $D_{\max }=0.5 \mathrm{~cm}$. Solutions of equations (8) and (9) are presented for various precipitation rates in Table 3 , which shows that the rate of increase of both $\rho$ and $I$ with $p$ is less than linear, owing to the shift of median drop diameters to higher values as the precipita- tion rate increases.

The precipitation currents and volume charge densities which must be provided by an acceptable theory of thunderstorm electrification have been considered by Mason (1953), Vonnegut (1963), Freier (1968) and several other workers. The concensus of opinion is that values of $\rho$ and $I$ of about 20 Coul. $\mathrm{km}^{-3}$ and $0.1 \mathrm{amp} \mathrm{km}^{-2}$ are necessary. These conditions are defined by the dashed line in Table 3. It is seen that both

Table 3 The variation with precipitation rate $p$ of the maximum volume charge density carried on precipitation, $\rho$, and the maximum charging current carried on precipitation, $I$. Marshall-Palmer distribution. The dashed line (-- ) delineates the approximate values of $p$ and $I$ which must be achieved by an acceptable mechanism of thundercloud electrification.

\begin{tabular}{c|c|c}
\hline $\begin{array}{c}p \\
\left(\mathrm{~mm} \mathrm{hr}^{-1}\right)\end{array}$ & $\begin{array}{c}\rho \\
\left(\text { Coul }^{\mathrm{k}} \mathrm{km}^{-3}\right)\end{array}$ & $\begin{array}{c}I \\
\left(\mathrm{amp} \mathrm{km}^{-2}\right)\end{array}$ \\
\hline 1 & 3.88 & 0.011 \\
5 & 10.6 & 0.040 \\
10 & 16.5 & 0.070 \\
20 & 25.6 & 0.12 \\
30 & 32.7 & 0.16 \\
40 & 39.7 & 0.20 \\
50 & 45.3 & 0.23 \\
70 & 56.1 & 0.31 \\
100 & 69.9 & 0.40 \\
200 & 107.3 & 0.67 \\
\hline
\end{tabular}

requirements are satisfied, assuming a MarshallPalmer distribution, if the precipitation rate exceeds about $15 \mathrm{~mm} \mathrm{hr}^{-1}$, corresponding to a precipitation water content of about $0.8 \mathrm{gm} \mathrm{m}^{-3}$. These values of $p$ and $L$ are generally achieved inside thunderclouds. Although leakage effects have been omitted from these rough calculations it is unlikely that the conclusions would be significantly modified by their inclusion.

The foregoing calculations have indicated that although the larger precipitation particles provide the major contribution to the radar return signal, the particles which are most important in producing the electrification will generally be quite small. This conclusion is consistent with that of Latham (1965), who showed that the riming mechanism of cloud electrification, which has been shown by Latham and Stow (1969) to play a 
dominant role in the electrification of thunderstorms in Northern Arizona, operates most effectively with precipitation particles of diameter less than about $1 \mathrm{~mm}$. In addition, the fact that the radar echo intensity increases very much more quickly than the electrification as the precipitation rate increases suggests that for distant storms electrification could be well developed before precipitation is detected and could then increase only slowly while the radar echo increases at a rapid rate.

The above analysis demonstrates that precipitation mechanisms are, in principle, capable of producing the electrification of thunderstorms. However, it does not follow that the production of intense fields within clouds is necessarily a consequence of the interaction of cloud particles. In order to resolve this question and to determine the importance of the dynamical mechanisms more field research is required.

\section{Acknowledgements}

The research described in this article was supported by means of a grant from the Natural Environment Research Council. I am also indebted to Dr W. W. Kellogg and Dr J. D. Sartor of the National Center for Atmospheric Research, Boulder, Colorado, who provided computational facilities; and to Professor Marx Brook of the New Mexico Institute of Mining and Technology, Socorro, New Mexico, for helpful discussions and advice.

\section{References}

Colgate, S.A., 1967: Enhanced drop coalescence by electric fields in equilibrium with turbulence. $J$. Geophys. Res., 72, 479-487.
Freier, G.D., 1968: The electrical structure of thunderstorms. Proc. Int. Conf, Cloud Physics, Toronto. 597-603

Gunn, R. and G.D. Kinzer, 1949: The terminal velocity of fall for water droplets in air. $J$. Meteor. 6, 243-248.

Latham, J., 1965: Electrification produced by the growth of soft hail in thunderstorms. Tellus, 17, 204-212.

- and C.D. Stow, 1969: Airborne studies of the electrical properties of large convective clouds. Quart. J. Roy. Meteor. Soc., 95, 486-500.

Marshall, J.S. and W.M. Palmer, 1948: The distribution of raindrops with size. J. Meteor., 5, 165-168.

Mason, B.J., 1953: A critical examination of theories of charge generation in thunderstorms. Tellus, 5, 446-460.

, 1957: Physics of Clouds. (Oxford Clarendon Press) 431-433.

Phillips, B.B., 1967a: Charge distribution in a quasistatic thundercloud model. Mon. Wea. Rev., 95, 847-853.

- 1967b: Convective charge in thunderstorms. Mon. Wea. Rev., 95, 863-870.

Sartor, J.D., 1967: The role of particle interactions in the distribution of electricity in thunderstorms. $J$. Atmos. Sci., 24, 601-615.

Vonnegut, B., 1953: Possible mechanism for the formation of thunderstorm electricity. Bull. Amer. Meteor. Soc., 8, 378-389. , 1963: Some facts and speculations concerning the origin and role of thunderstorm electricity. Meteor. Monogr. 5, 224-241. , 1965a: Thundercloud electricity. Discovery, (March Issue).

- 1965b: Electrification of frost deposits. Quart. J. Roy. Meteor. Soc., 91, 369, 372-374. , 1965c: Problems of Atmospheric and Space Electricity, Ed. S. Coroniti, Elsevier Press, Amsterdam, 285-292. 


\title{
雷雨帯電の降水機構の定量的評価
}

\author{
J. $レ$ - サ ム \\ マンチェスター大学, 英国
}

Marshall-Palmer の雨滴分布の式と Sartor（1967）の固体粒子と液相降水粒子の空間密度を用いて降水粒子の帯 電率えの寄与を計算した。 ぞの粒径の降水粒子が带電率にまた降水があるときの最大帯電空間密度に寄与している かを計算した。

雲の成長中の各段階において, 帯電に主要な寄与をする粒経は小さいことがわかった. $10 \mathrm{~mm} / \mathrm{hr}$ の降水強度に対 して直径 $0.1 \mathrm{~cm}$ より小さく, 降水強度 $200 \mathrm{~mm} / \mathrm{hr}$ の非常に活発な雲の中でさ兄最適の粒経は $0.2 \mathrm{~cm}$ 以下である. 一方レーダ ェコー強度に主に寄与寸る降水粒子の直経は降水強度が $10 \mathrm{~mm} / \mathrm{hr}$ から $200 \mathrm{~mm} / \mathrm{hr}$ にいたる間で 0.25 $\mathrm{cm}$ から $0.42 \mathrm{~cm}$ である.

計算の結果, すでに数人の研究者によって理論的に示されている. 降水流と帯電空間密度の值は約 $15 \mathrm{~mm} / \mathrm{hr} の$ 降水強度の降水機構の働いている時達せられる.これは降水含水量 $0.8 \mathrm{gr} / \mathrm{m}^{3}$ に相当する. 